\title{
E-Governance: A Tool for Confiscating Tribulations in Higher Education in India
}

\author{
Prateek Bhanti, \\ Mody Institute of Technology \\ and science \\ Laxmangarh, Sikar
}

\author{
Sushma Lehri, PhD \\ Dr. B. R. Ambedkar \\ University, Agra \\ Email
}

\author{
Jelsey Joseph, PhD. \\ Mody Institute of Technology \\ and science \\ Laxmangarh, Sikar
}

\author{
Narendra Kumar, \\ $\mathrm{PhD}$ \\ Mody Institute of Technology \\ and science \\ Laxmangarh, Sikar
}

\begin{abstract}
E-Governance has proved to be a boon in various areas like Municipalities, Transport etc. Higher education is one such area which requires serious reengineering of work culture. The essence of this paper is to identify the problems with which the higher education system of India is struggling. The author attempts to provide an E-governance conceptual framework for the elimination of various problems in higher education. The introduction of e-governance in higher education can open the way for good-governance and the government can improve the service delivery through the use of Information and communication technology.
\end{abstract}

Keywords: E-Government, Information technology, problems, framework, problems in governance.

Objective: The objective of this paper is to identify various tribulations faced by stakeholders of higher education in India and examines the possibilities of implementation of $\mathrm{e}$ governance in Higher education sector as solution

\section{INTRODUCTION}

The issue of governance in higher education of late has become a matter of academic administrative debate on a wider scale for various reasons. Technology and transparency are two vital inputs having the potential to transform the system of higher education into a vibrant space for learning knowledge and research. The sophisticated technological tools and applications not only track and process the data and information but also report on the different aspects of academics as well as administrative activities.

E-governance can be defined as a way for the governments to use the most innovative information and communication technologies, particularly web-based Internet applications, to provide citizens and businesses with more convenient access to government information and services, to improve the quality of the functioning and to provide greater opportunities to participate in democratic institutions and processes[1].

\section{Methodologies/ Approach:}

In order to collect the data, an extensive content analysis is conducted. The analysis includes the review of literature of many authors through journals, research works, articles, online information, published books, magazines etc. The literature looked into the problems related to governance and operation of higher education system Desk research through the study of theory and discussion with officials of government agencies like National Informatics Centre, CDAC and other private organization helped in consolidating the fact that the E-Governance can enhance the quality of education services in India.

\section{MAJOR TRIBULATION}

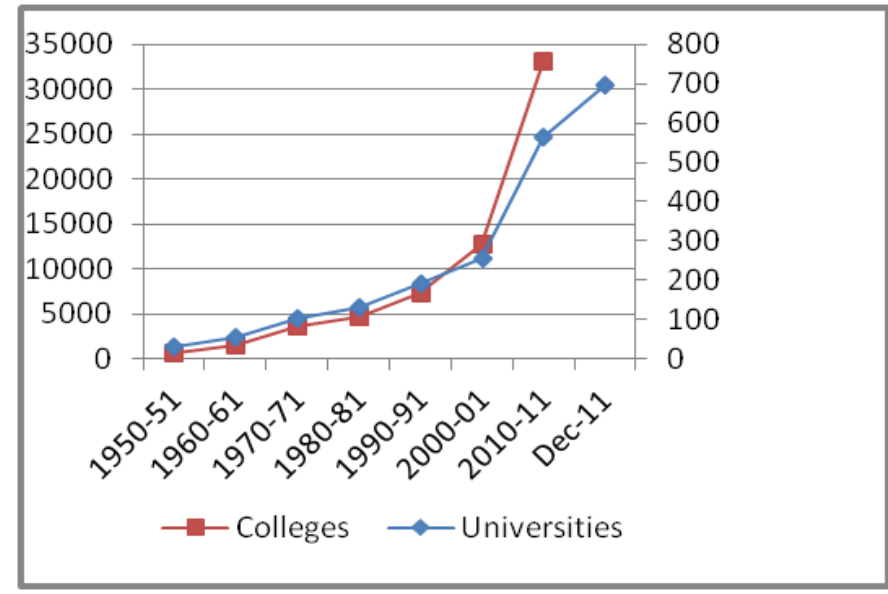

Source: UGC/MHRD

Figure 1: Growth of Colleges \& Universities in India

Access to higher education was very limited before independence. The report, 'Higher Education in India at a Glance' prepared by the Chairman, Ved Prakash and other senior UGC members, highlighted the statistics related to higher education in the country in terms of number of institutions, type of institutions etc. There is a $20 \%$ increase in the number of degree granting universities and this number is more than doubled from 256 to 564 in a decade which finally roused up to at 634 by the end of 2011 .

India has a diverse affiliation system where universities can affiliate many public and private colleges [2]. The graph reveals that there is a noticeable increase in the number of degree granting universities and colleges since independence. Nearly 20,000 colleges in a decade has been added which is actually an increase of nearly $150 \%$ [3]. The number of universities and colleges are still not sufficient to cater the needs of the growing number of aspirants. Hence, still we need to have more universities and colleges.

While talking about the growth in student enrolment the report states that in 1950 the total number of students enrolled in higher education institutions was $3,97,000$. The growth was steady till 2001 and stood at 83, 99, 000 but then saw an extraordinary course in next 10 years. 


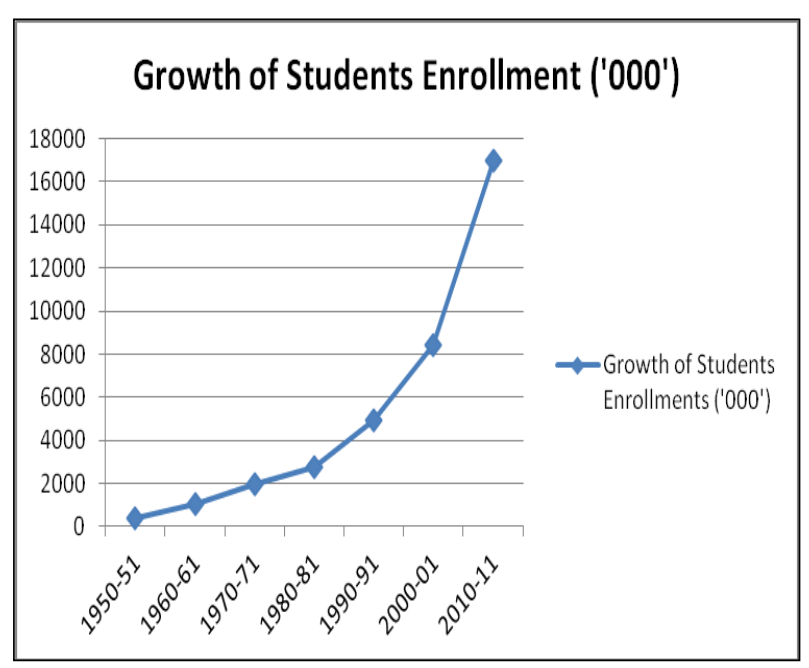

Source: UGC/MHRD

\section{Figure 2: Student enrollment}

The enrolment explosion and the huge number of colleges and universities have created higher responsibility and pressure on the government for managing and controlling higher education sector. Higher education in India is managed and monitored by the UGC and the various other Councils [4]. These councils namely AICTE, MCI, BCI etc., in different areas are primarily responsible for controlling and monitoring these higher education institutes.

\subsection{Recognition / Accreditations}

UGC has developed a mechanism of accreditation in order to evaluate performance of an institution and bring about a measure of accountability. National Accreditation and Assessment Council (NAAC) has been established by UGC with a purpose to carry out a periodic assessment of universities and colleges. Similarly, for technical education AICTE has established its own accreditation mechanism through the National Board of Accreditation (NBA) for benchmarking the performance [5].These councils, with the exception of some notable ones, have however, not being able to maintain the high educational standards.

Mishra et. al.(2008) [6] highlighted the irony in India that a large number of institutions without having adequate infrastructure are not only surviving but running successfully. He advocated the development of a system which can address the challenges of quality and inefficient systems of monitoring and control.

Moreover, the institutes/ Universities also find it difficult to cope up with the separate regulatory bodies. Similar types of documents are required to submit in these agencies which lead to the enormous waste of time and money.

Rajeev Singh[7] highlighted the problem of duplication of procedure for getting approval / renewal from various regulating bodies. He emphasized on the need of faster and preferably paperless process of approval and accreditation. At present the mechanism is leading towards more corruption and political interference. More transparency is needed in the operations of these councils.

\subsection{Demand of course and Employment generation}

The government needs to keep records of all the students, universities, colleges, teachers etc for various decisions making and planning for future employment. This type of data may be useful for placement companies and other organization for recruitment purpose also.

With the increasing number of enrolments and different trend of demand of course, it is very difficult for the government to take decisions about the issues like employment generation. Government has no mechanism to track the course in demand as and when required especially when universities are not linked and information about all the students and the opted courses are not centralized.

D R Goel and Chaya Goel [8] in their article stated that there is demand and supply gap which may be probably due to the reason that there is no mechanism for keeping the record of the enrolled students for future planning.

There is no uniformity as far as admissions to the universities are concerned. Besides National level test for Medical and Engineering, private universities and the universities running under state government conducts there separate admission test. This again leads to wastage of time and money as far as children and their parents are concerned. Although MHRD has been thinking of conducting one test and prepare a common list for successful candidates so that candidate can have a choice of his/her institute based on his / her resident's proximity and quality of the institution. In order to conduct such a test at National level, a tremendous amount of data needs to be managed .Such huge flow of data can only be managed through the use of ICT.

\subsection{Misleading Information}

Chadha Rajat [9] views the university website as of prime importance to prospective students to find out what programme of studies are available at the institute. The colleges and universities display insufficient and misleading information about their infrastructure, placements and other facilities in the universities. It is also seen that in some cases there are certain hidden charges besides fee displayed on the university website.

\subsection{Regional disparity}

K Shanthi(2008) [10] discussed various aspects of higher education that requires in-depth study. The students from more progressive states and from urban background have better chances of getting good education and better job prospects. The other aspect of reforms which according to him needs attention is the introduction of courses that meets the demand of the day.

Richard James(2001) [11] did a study to examine the effect of the intersection of socioeconomic status and residential location. It also includes the effect of distance from a university campus and contextual location. Study found that a cumulative discouraging effect caused by the coincidence of lower socioeconomic background, and distance from a campus.

Rajeev Singh[12] tried to break the myth that smaller colleges do not have bright and employable students and suggested the governing bodies to provide a common platform to the industry to recruit.. The author suggested a metric to assess the performance of a university on an overall basis and 
on the basis of courses offered. As far as strategic challenges are concerned, the need is to obtain the trend of selection of a particular course by students which can enable the governing bodies to plan accordingly. The author concluded that ICT has played a major role in reducing operational efficiency and improving decision making in many areas of governance.

\subsection{Fund disbursement}

In last four decades, huge amount of funds have been given to the educational institutes for their development. But it has been seen that the institutions are not able to utilize the funds, there is a lack of transparency in the allocation of funds and its expenditures.

No administration can claim to be accountable, responsive and student friendly unless it establishes an efficient and effective grievance redress mechanism. Grievance redress mechanism is the measure of the effectiveness of the administration.

\section{Research Gap:}

The literature review served to identify the key research issues. Although there was sufficient scholarly research literature available in the form of reports, case studies, research papers, and articles on the web but most of them are only focused towards the identification of problems in the higher education. It appeared that very little prior research was done to explore the possibility of developing the framework towards successful implementation of EGovernance as an initiative in higher education system at a National level.

\section{E-Governance in Higher Education: A Road Map for confiscation}

The challenge of management of the records of the candidates are large in front of authorities and Information and communication technology (ICT) may prove to be boon for this. The problem of lack of transparency and corruption can also be managed by the use of ICT.

Pradeep kumar Mishra(2012) [1] augurs the need of a comprehensive plan to bring E-Governance culture for the above mentioned problems. He suggested that the researchers must evolve a mechanism, and a simple and easily executable plan of action, as a way of improving performance in higher education sector in India. This culture of E-Governance in higher education sector can be implemented by administrators and academicians.

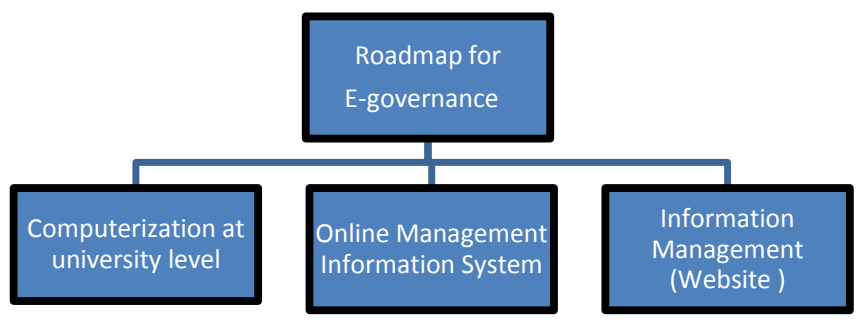

Figure 3 : Road map for E-Governance in H.E.

(a) Computerization at University Level:
Computerization of university is assuming an ever increasing role as the demands being placed on university escalate, the reason of the demands may be due to the increasing number of students and greater demands for sound fiscal management and planning. Modern technology like, optical fiber cabling, Wi-Fi shall be used in order to connect the departments in campus as well as with the outer world through internet [14].

The most important application areas in priority order are related to students, staff and administration. Following figure depicts activities included in computerization of universities

The process of computerizing a university or an entire system of higher education involves changes in both technology and procedures.

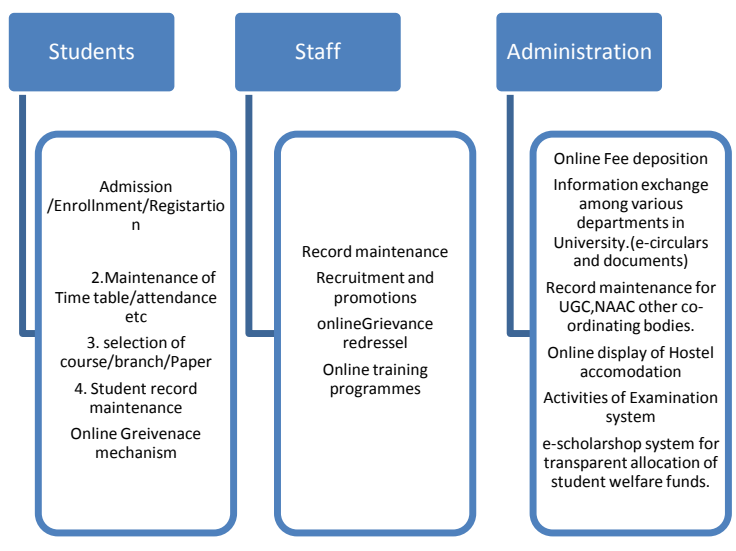

Figure 4: Modules included in computerization of university.

Hence, in order to implement the information system for various purposes, university requires a complete procedural re-engineering.

In view of limited resource and revenue, the computerization of universities would be more challenging. The digital divide will multiply this challenge in reaching a larger segment of the stakeholders, especially the students. Lack of infrastructure, scarcity of local technical expertise, unnecessary bureaucratic and weak legal supports will make it more difficult for universities in India to implement EGovernance[15].

\section{(b) Online Management Information System:}

The function of a Online Management Information System is to support and study information relating to:

- Enquiries from prospective students

- Management of admissions process

- Registration of students and storing their data with their teaching option choices

- Handling records of examinations, grades etc.

- Maintaining records of faculties and handling enquiries

- Interaction with students

- Providing statistical reports

- Interacting parents through a parent portal 
- Knowledge resources including library

- Affiliation function

- Administrative functions

- Personnel management system

- Budget / accounts / finance / treasury and audit system

(c) Information Management: It is collection, management, and distribution of Information to one or more audiences. This involves those who have a stake in, or a right to that information. Information Management in Higher education should include

a. Information about the Regulatory bodies under Ministry

b. Information about the norms / rules / regulations / deadlines pertaining to courses, funds Information about the faculty members of all universities.

c. Information about the courses / Syllabi

d. Information about admission in various universities.

e. online submission of applications

f. Library resources

g. Activities including seminars / conferences / alumni. h. Information on the schemes of the government like Career Information on Courses offered.

i. Admission process, Fee details and other admission related information.

\subsection{E-Governance Conceptual framework for Higher Education System}

Figure 4 illustrates the broad-brush picture of proposed higher education system. Inputs required by the system will be provided by the stakeholders and universities or Colleges. The inputs may include students' profile, Faculty Profile, University or College profile, Infrastructural Specification, Courses, admission data, passed out student data etc. This data will be stored at a centralized location so that Higher education system may access the data to fulfill the expectations. The output of the conceptual is a set expectation describing the model in detail to begin the work on detailed design

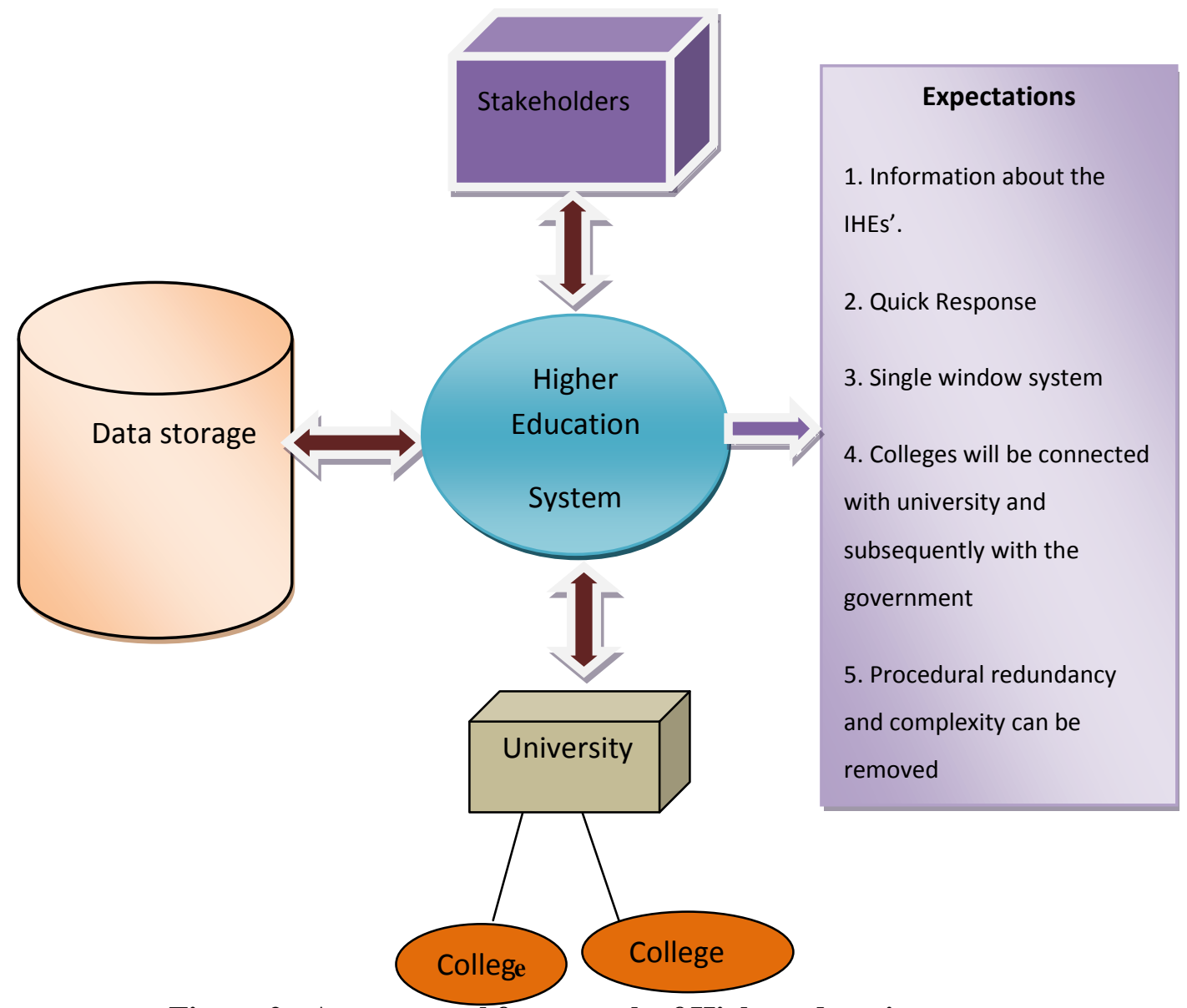

Figure 2 : A conceptual framework of Higher education system 


\section{FINDINGS}

This study will be a significant endeavor in promoting EGovernance culture in Higher Education system in India. After introduction of such a system, the procedures can be cut down since all the statistics about the resources of the university will be made online. The proposed E-Governance model can provide the mechanism which will be automated or time bound because all details needed for the approval of funds can be fetched by the centralized system in online fashion. By using a centralized database of students, governing bodies can provide an opportunity to bright students. The centralized database system will provide a common platform to the bright students and job consultants. The governing bodies and industry can very easily get the details of bright students from all over in India in various fields. The trend of demand of course or stream can be easily tracked as and when required when universities are linked and information about all the students and the opted courses are centralized. The governing bodies can very easily develop a mechanism to analyze which course is in heavy demand in a particular area or region. Government can plan the generation of employment according to the passing graduates in the country. The E - governance interface can be used to get the feedback from the students related to the course and performance of university. Students can directly give their feedback about the performance of the universities/ colleges to the regulatory bodies.

\section{CONCLUSIONS}

It is expected that implementation of such type of EGovernance initiative in the right spirit will not only eradicate the problem but also prove to be a milestone in the development of higher education in India. Although there are certain rumble strips in the above roadmap like lack of awareness, lack internet connectivity and lack of other infrastructural resources in colleges/ universities. But in due course of time, the government will be able to handle these shortcomings and thus above system may produce all the benefits which are expected.

\section{ACKNOWLEDGMENTS}

The authors are thankful to all those who have inspired us to write this paper.

\section{REFERENCES}

[1] Zhiyang Fang, " E-Government in Digital Era: Concept, Practice, and Development", International Journal of The
Computer, The Internet and Management, Vol. 10, No.2, 2002, p 1-22

[2] Choudaha, D. R. (n.d.). latest-statistics-indian-higher. Retrieved october 21, 2012, from Blog of rahul Chaudaha: http://www.dreducation.com/2012/06/lateststatistics-indian-higher.html

[3] India bizclub (n.d.). Structure of education. Retrieved 2013, from education.indiabizclub: http://education.indiabizclub.com/info/structure_of_educ ation

[4] (n.d.). Retrieved from University Grants commission: www.ugc.ac.in

[5] Ujjaini sahasbudhe, s. m. (n.d.). Making sense for accreditation for higher education in India. International reserach foundation , 1-4

[6] Jitendra Kumar Mishr, N. A. (2008). Indian Higher Education: Global Challenges and Local Issues. JBS working paper series, New Delhi.

[7] Singh, R. (n.d.). Retrieved october 10, 2011, from egovcoe: www.egov-coe.ncc.gov.ph

[8] Goel, D. R. (2008). Higher Education: Problem and Prognosis. University News , 46 (37), 14-20.

[9] Chadha, Rajat(2008). Wake up call for Indian University Administrators ?: A study of Indian University Websites. University News, 46(49),1-7

[10] Shanthi, K. (2008). Issues and Challenges in Higher Education. University News , 46 (38), 19-23.

[11] James, R. (2001). Participation disadvantage in Australian Higher Education: An Analysis of some effect of Geographical Loaction and socioeconomic Status. Higher Education, Vol 42, No. 4 , 455-472.

[12] Mishra, P. K. (2012). Promoting e-Governance culture in institutions of higher education: Why and How. University News , 50 (46), 23-26

[13] Singh, R. (n.d.),op cit achuthan, S. (1993). Computer Technology for Higher Education: A Design Model for a Computerizing University, Volume 1. Concept publishing company.

[14] Subrata Kumar Dey et al, "Conceptual framework for Introducing e-Governance in University Administration",ICEGOV2008, December 1-4， 2008, Cairo Egypt 